\title{
PLANEAMIENTO ESTRATÉGICO EN LA ERA DE LA INFORMACIÓN
}

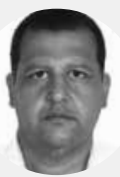

\author{
VICTOR H. JAIME \\ - Profesor de Planificación Estratégica y Modelos de Negocio \\ Área Académica de Administración \\ Facultad de Negocios, UPC
}

El planeamiento estratégico ha prevalecido en el mundo de las empresas desde el año 1960, aproximadamente. Se le dio importancia a partir de la necesidad empresarial de proyectar el futuro y de prever situaciones exógenas que influían en el logro de sus objetivos. Por ejemplo, se planteó una metodología a través de la propuesta de Albert Humphrey para analizar el ambiente externo e interno de la empresa. Se hacía un análisis de factores externos generales y otros más específicos vinculados a la dinámica competitiva y a las fuerzas que se ejercen con los clientes y los proveedores. El análisis interno se enfocaba en los recursos y las capacidades de cada empresa.

Humphrey lo hizo por la preocupación que había en esos años (post Segunda Guerra Mundial), en los empresarios y directores de empresas sobre la visión de corto plazo que predominaba en la gestión empresarial de entonces.

Por encargo del Instituto de Stanford, se hizo la investigación que concluye que había que hacer un análisis externo e interno a las empresas como parte del proceso de planeamiento empresarial que derivaba en una matriz FODA (Fortalezas - Oportunidades Debilidades - Amenazas), con el objeto de poder predecir el futuro a un plazo largo (lo más largo posible). La gestión empresarial empezó a mirar estos plazos con mayor confianza y logró hacer un plan cuyo horizonte tenía en promedio cinco años de tiempo.

Así mismo, existía la necesidad de darle un horizonte claro. El problema no era sólo el tiempo sobre el cual se podía predecir el futuro. Había que darle una razón de ser a los colaboradores. Debían encontrar un sentido a cada una de las tareas que desarrollaban. Antes de este modelo de planeamiento (antes de 1960), las empresas se enfocaban en sus presupuestos y en acciones multianuales (corto y mediano plazo). Después de implementar el análisis FODA como parte del planeamiento se incorporó la declaratoria de visión y misión dentro del proceso de planeamiento estratégico.

Junto a esos estudios, Michael Porter, considerado el padre de la estrategia competitiva, creó el paradigma de las estrategias genéricas de diferenciación o liderazgo en costos en su obra celebre, La ventaja competitiva. Las estrategias genéricas o competitivas son hasta hoy parte indispensable dentro de una empresa para alinear el esfuerzo de cada uno de los colaboradores que realizan actividades dentro de los eslabones de una cadena de valor.
Dicho de otra manera, Porter, mediante sus estrategias competitivas, logró que las empresas puedan alinear sus esfuerzos en busca de los objetivos planteados y en busca de su propia visión y misión.

Sin embargo, este esquema no fue suficiente. Las empresas demandaban estrategias empresariales que ayuden a los empresarios y directores de empresas a tomar decisiones sobre las acciones futuras. Igor Ansoff (1918 - 2002), considerado un pionero de la introducción de la cultura del pensamiento estratégico en el mundo empresarial y académico, y uno de los primeros autores en publicar un libro sobre estrategia empresarial, introdujo los conceptos y términos que han servido de base para todo el amplio desarrollo en el área estratégica. La matriz Ansoff nos permite pensar en estrategias de penetración de mercado, desarrollo de producto, desarrollo de mercado y/o diversificación.

A partir de estos pensadores, tanto Fred David, Charles W. L. Hill y Gareth R. Jones, entre otros, han propuesto modelos de planeamiento donde se aterrizan estrategias genéricas y también empresariales en sus textos sobre administración estratégica que son utilizados en las facultades de administración y escuelas de negocios del mundo entero.

Pero ¿cuán desarrollada estaba la Tecnología de la Información en el mundo entre los años sesenta y los años setenta? ¿Cuánto se utilizaba la tecnología de la información en la gestión empresarial en esos años? ¿Cuán desarrollado estaba el concepto de globalización?

Hay que recordar que en esos años el mundo estaba dominado por la industrialización como concepto. Las empresas se enfocaban en la producción de bienes y en su comercialización. Existía la necesidad de generar ambientes competitivos en los países para que las empresas se pudieran desarrollar. Eran momentos donde los conceptos de competitividad nacían y se posicionaban en el mundo corporativo. Los mercados eran estables y se podía pensar en sectores que garantizaban una vida para las empresas mayor a cinco años. La tecnología de la información todavía no había penetrado en las empresas desafiando lo existente. Por ejemplo, empresas dentro del sector cervecero sabían quién era su consumidor y lo que le gustaba. Empresas como Cristal y Pilsen en el Perú competían directamente y podían desarrollar sus planes estratégicos utilizando el FODA como herramienta fundamental de análisis. 
La globalización era un concepto futurista y no se entendía como una forma de integrar al mundo comercialmente. La tecnología de la información todavía no había "unido" el mundo a través de sus redes y establecido nuevos modelos de negocio basados en la Internet y otras tecnologías de comunicación e integración. Por ejemplo, los supermercados Wong existían en Perú y no tenían como parte de su visión que vengan supermercados como Wal Mart a competir al Perú.

En un ambiente sin tecnología de la información, la planificación "garantizaba" (o aumentaba la probabilidad), de una ejecución estratégica exitosa en el largo plazo. Había certidumbre sobre los eventos que se daban en el ambiente competitivo. La conducta del consumidor era más predecible y respondía a los estímulos de la empresa según los medios tecnológicos del momento. El plan estratégico esperaba el desarrollo del plan de marketing para analizar a profundidad al consumidor y su comportamiento, quienes formaban parte de un análisis táctico y no estratégico.

¿Qué ha cambiado? Que hoy estamos en la era de la información y del conocimiento. El sociólogo, Manuel Castell, en su libro El estado de bienestar y la sociedad de información señala que estamos frente a un cambio estructural de la sociedad. Las fronteras de los países ya no existen. El mercado es el mundo y desde el mundo se maneja mucha información. Los sistemas de comunicación, los sistemas informáticos, han cambiado el mundo, dominado por la industrialización, a un mundo dominado por el conocimiento y las comunicaciones. Los países desarrollados han evolucionado a través de la innovación a una sociedad que valora las patentes y el conocimiento como base del desarrollo y no las grandes industrias. Las empresas de hoy deben entender estos cambios y modificar su sistema de planeamiento estratégico. Steve Jobs cuando inventó el iPod o el iPad ¿habrá pensando en su estrategia genérica? Cuando Michael Dell cambió las reglas de juego en el mercado de las PCs, ¿habrá pensando en sus estrategias genéricas? Yo creo que no. La innovación es un componente que debe estar presente en el proceso de planeamiento estratégico pero considerando un mundo nuevo; un mundo interconectado. Ya no se puede pensar en el planeamiento estratégico como en el año de 1960. Hoy los plazos o el horizonte del planeamiento se reducen dramáticamente. La industria de las PCs o las laptops se ve amenazada por la de las tabletas. ¿Qué más viene? Solo los que están en esa industria saben que su planeamiento no puede hacerse con un horizonte de cinco años. ¿Serán suficientes las estrategias de Ansoff para el avance empresarial?

\section{LA INNOVACIÓN ES UN COMPONENTE QUE DEBE ESTAR PRESENTE EN EL PROCESO DE PLANEAMIENTO ESTRATÉGICO PERO CONSIDERANDO UN MUNDO NUEVO; UN MUNDO INTERCONECTADO.}

El comportamiento de los consumidores ha cambiado. Hoy las decisiones se toman en función de una generación dominada por las "comunicaciones inmediatas". Todo es "online". Existe una mayor cantidad de información y las redes sociales pueden difundirla de manera inmediata. Ha cambiado el consumidor y con él ha cambiado el mercado. El análisis del micro-ambiente según el modelo de proceso secuencial tradicional de planeamiento, ¿no debería evolucionar más allá del análisis de las cinco fuerzas de Porter o del análisis de la dinámica competitiva?

El planeamiento estratégico que sigue la metodología tradicional tiene cada vez más dificultades para adaptarse a los cambios dinámicos de las empresas y de los consumidores. Estamos frente a un ensanchamiento de la brecha entre el planeamiento y la ejecución y una de las razones es que no se está haciendo un análisis estratégico del mercado y del comportamiento del consumidor en un entorno donde la tecnología de la información es el primer factor de incertidumbre sobre el futuro.

Es indispensable hacer un análisis más profundo sobre el consumidor y su comportamiento desde la etapa del planeamiento que busca identificar oportunidades y amenazas. Hay que hacerlo antes de la formulación estratégica. El análisis del micro-ambiente debe incluir al consumidor y a su comportamiento. El análisis del microambiente debe hacerse más allá de las cinco fuerzas de Porter. Hoy se deben incorporar herramientas como las propuestas por Kim Warren, en su libro Strategy Dynamics Essentials, o metodologías que te obligan a cuestionar a los consumidores desde la perspectiva de sus problemas y de su solución a nivel de hipótesis como lo propone Steve Blank en su teoría del "Customer Development". Hay que buscar "océanos azules" como lo propone W. Chan Kim en su libro Estrategias del Océano Azul. 


\section{EL PLANEAMIENTO ESTRATÉGICO QUE SIGUE LA METODOLOGía TRADICIONAL TIENE CADA VEZ MÁS DIFICULTADES PARA ADAPTARSE A LOS CAMBIOS DINÁMICOS DE LAS EMPRESAS Y DE LOS CONSUMIDORES.}

Este análisis provocará una dimensión diferente en el análisis de los clientes que va más allá del poder de negociación. Nos llevará a conocer al consumidor y a entender las oportunidades y amenazas que se presentan a partir de su comportamiento. El análisis de productos substitutos se hará pensando en la conveniencia del consumidor. Lo que se empieza a sustituir en muchos casos son las formas en las que se brindan servicios. Es lo que pasó con Netflix cuando sustituyó el servicio de arrendamiento de Blockbuster. Los consumidores actualmente se adaptan muy rápido a una nueva propuesta y abandonan con la misma velocidad las propuestas antiguas (donde "antiguo" significa un año). Las barreras de entrada cada vez tienen menos que ver con los niveles de inversión o con el conocimiento adquirido. En la era de la información, las personas y las empresas aprenden cada vez más rápido y están listas para copiar cualquier actividad. Los proveedores son más globales y tienen a su disposición más información sobre sus clientes. El análisis de los proveedores debe ir más allá del poder de negociación.

Me parece que el planeamiento estratégico, tal como está ahora, tiene sus días contados. La velocidad en que cambian los gustos del consumidor y, por tanto, el valor que éste le impone a los bienes y servicios, nos obliga a desarrollar procesos diferentes de planeamiento. Hay que desarrollar nuevos procesos de investigación de mercado. Hay que comenzar por entender al cliente en su dinámica actual. Hay que entender, es decir, cómo cambia el consumidor, sus drivers, sus motivaciones de cambio, antes de tomar una decisión de largo plazo como se hacía antes. 